\title{
A ARTE PÚBLICA E A MATERIALIZAÇÃO DAS MEMÓRIAS HISTÓRICAS NA CIDADE DE MARINGÁ*
}

\author{
Sandra C. A. Pelegrini \\ Universidade Estadual de Maringá \\ Centro de Estudos das Artes e do Patrimônio \\ Cultural - CEAPAC/UEM \\ Pesquisadora do NEE/U N ICAMP
}

\section{Resumo:}

A paisagem urbana e as manifestações artísticas inseridas nas áreas públicas oferecem ao pesquisador elementos capazes de suscitar a reflexão acerca das representações das memórias históricas e sobre as identidades forjadas no espaço citadino. Nesse sentido, o presente artigo visa a analisar os referenciais identitários materializados nos espaços públicos de Maringá (Pr), privilegiando algumas das produções artísticas instaladas em vias públicas e praças da cidade.

Palavras-Chave: Arte pública; Imagem; História; Memória.

The public art and the materialization of the historical memories in the city of Maringá

\begin{abstract}
:
The urban landscape and the artistic manifestations inserted in the public space offer to the researcher elements capable to raise the reflection concerning the representations of the historical memoirs and about the wrought identities in the town space. In this sense, the present article seeks to analyze the references of the identity materialized in the public spaces of Maringá (Pr), privileging some of the artistic productions installed at public roads and squares of the city.
\end{abstract}

Keywords: Public art; Image; History; Memory

\footnotetext{
* Essa reflexão constitui parte integrante da pesquisa "A arqueologia de uma cidade. O Patrimônio cultural de Maringá, memória e fruição (1947-1999)", desenvolvida como parte dos estudos do pósdoutorado, sob a supervisão do Prof. D r. Pedro Paulo Funari, entre 2005 e 2007, no N EE/U N IC AM P, com apoio do CN Pq.
} 
A memória humana pode ser reavivada por meio de distintas sensações, sonoridades, odores, sabores, diferenciadas formas de representação visual e cenográfica do urbano. No entanto, a memória socialmente construída não raro aparece associada às lembranças vinculadas a monumentos e lugares específicos da cidade. A escolha do nome das ruas e praças, ginásios de esporte e demais espaços públicos da cidade podem indicar representações de mitos fundadores, marcos identitários e referências culturais urbanas. De maneira correlata, a observação atenta das manifestações artísticas inseridas no espaço público é capaz de fornecer pistas valiosas sobre os modos de se pensar a história da cidade e se vivenciar esse espaço.

Os silêncios e as ausências de celebrações são igualmente reveladores. Certo é como assinalam os estudiosos dessa temática, que tal 'tradição' tem sido tomada como uma prática pedagógica, um meio de rememorar fatos, negar episódios, enaltecer personagens ou relegá-los ao esquecimento. Os elementos da paisagem urbana e sua visualidade permitem que os transeuntes interpretem, no campo simbólico ou cognitivo, imagens, memórias e histórias da cidade. Nessa direção, a presente reflexão ocupa-se da discussão de alguns referenciais identitários materializados nos espaços públicos da cidade de Maringá, privilegiando algumas das produções artísticas instaladas nesses locais.

\section{A ARTE E O ESPAÇO PÚBLICO.}

Antes de nos ocuparmos de tais objetivos, devemos reconhecer que o trato dessa problemática implica o enfrentamento de não poucos desafios teóricos e metodológicos que pressupõem, entre outros aspectos, a percepção das noções que envolvem a definição do espaço e da arte pública. Ante o exposto, salientamos que embora Maringá tenha sido estrategicamente desenhada a partir de um projeto urbanístico que previa a tipificação do zoneamento e a hierarquização do solo, com vistas a uma ocupação racional e ordenada, não podemos ignorar que as relações sociais, determinadas historicamente, foram decisivas na definição da forma e do sentido social atribuído ao espaço ${ }^{1}$. E também, que o urbanismo se constitui de um sistema de idéias legitimados pela ciência, capaz de dissimular estratégias associadas aos discursos e práticas informadas por interesses de clas$\mathrm{se}^{2}$. Em essência, os pressupostos conceituais constituintes da arte pública assentam-se nas relações que esta é capaz de estabelecer com o espaço no qual está inserida e com o cidadão que habita a cidade. Nessa linha de abordagem, constatamos que a mesma acaba contribuindo de alguma maneira para conferir certa singularidade ao lugar ou ao desenho da cidade ${ }^{3}$. No entanto, não devemos negligenciar que a conotação atribuída à arte pública, não raro, a reduza à cenografia urbana, nem tampouco que a postura deliberada de ocupar a cidade e 
transformar os espaços públicos em suportes da memória oficial atenda a interesses de determinados segmentos sociais.

Posto isso, lembramos que o desenvolvimento industrial processado ao longo da segunda metade do século XIX, sem dúvida, impulsionou o crescimento dos aglomerados humanos, o surgimento de inúmeras cidades e com elas novas necessidades urbanas. Mas, no século XX, tais imperativos difundiram preocupações com a estética e o desenho das cidades ${ }^{4}$, favorecendo a criação de espaços livres como praças ajardinadas, onde se tornaram muito comuns a inserção de esculturas comemorativas e monumentos com fins decorativos e pedagógicos. De outra parte, o reconhecimento do status social da $a^{5} e^{5}$, bem como a proliferação da fundição impulsionou a ornamentação de relógios, gradis, fontes, chafarizes e luminárias. Estes acabaram difundindo "padrões de gosto cosmopolitas" em diversos ambientes citadinos ${ }^{6}$.

O hábito de ocupar o espaço urbano com esculturas adquiriu especial repercussão na França, na segunda metade do século XIX. A partir de 1870, a demanda de peças sugeriu a caracterização da denominada "estatuamania", designação que consolidou a celebração de personagens históricos republicanos como iniciativa de caráter político-pedagógico ${ }^{7}$. Por certo, tanto na capital da República francesa, como na da brasileira, a inscrição da estatutária pública, inicialmente, buscou a reforçar simbolicamente os vínculos entre o Estado e a sociedade civil. A estátua eqüestre de D. Pedro I, na atual Praça Tiradentes (1862) e o tributo a José Bonifácio como patrono da Independência, no largo São Francisco (1872), foram inaugurados no Rio de Janeiro com esse intuito ${ }^{8}$. No decorrer do século XX, a produção escultórica se proliferou por outras cidades do país, mas adotou os mais diversos estilos e técnicas.

Se nas décadas de 1940 e 1950, os debates sobre a planificação e a implementação de zoneamentos pautados pela hierarquia funcional urbana se intensificaram, nos anos sessenta o próprio conceito de arte pública como gênero artístico adquiriu novos aportes à medida que os processos de recepção e circulação da arte foram colocados em xeque pelos adeptos da Pop-Art e da Arte Conceitual ${ }^{9}$. Alguns especialistas assinalam que os movimentos de maio de 1968 constituíram um marco na história da 'arte pública' concebida como forma de expressão urbana, particularmente, quando minorias étnicas, raciais e sexuais passaram a usar os murais para sinalizar suas preocupações sociais, manifestar suas visões de mundo e suas experiências estéticas ${ }^{10}$. Contudo, não podemos esquecer que as primeiras noções de arte pública se manifestaram na Antiguidade, e posteriormente, tiveram suas concepções vinculadas aos estudos de urbanística das décadas finais do século XIX sugeridos por Camilo Site ${ }^{11}$ e às propostas difundidas sob o signo da popularização artística e da defesa de uma arte acessível a todos ${ }^{12}$. 
Como bem o lembram Vera M. Pallamin e César Floriano dos Santos ${ }^{13}$, o intento de promover a qualificação da paisagem e a humanização das cidades, manifesto na década de 1960, estimulou inúmeras instituições públicas e privadas, em especial, os grandes conglomerados industriais, a desenvolver programas de instalação de obras de arte no espaço urbano. Do ponto de vista da construção da memória citadina, a inserção dessas obras no espaço urbano pode ser abordada mediante a interpretação de marcos identitários de determinadas cidades e como formas de diversificação da linguagem artística que se ocupa das representações do espaço urbano. O signo da memória impregnado em tais monumentos, como destacou Marilena Chauí, constitui marcos de uma das mais fundamentais experiências do tempo, representando a capacidade humana de retê-lo ou guardá-lo, livrando-o da "perda total" ${ }^{14}$.

Convém considerarmos também que a própria cultura urbana se redefiniu mediante o papel atribuído à urbanística pelos profissionais da área, nas décadas iniciais do século XX. Em meados de 1933, realizou-se na Grécia, um evento internacional que resultou na confecção de uma significativa abordagem acerca da relação entre a arte, a preservação do patrimônio histórico e a expansão das cidades, pois inseriu a questão no âmbito do planejamento físico e territorial das áreas urbanas. Concebida durante a realização do IV Congresso Internacional de Arquitetura Moderna, após uma série de outros eventos organizados por arquitetos interessados em debater paradigmas da arquitetura moderna frente aos problemas decorrentes do crescimento acelerado das metrópoles, a Carta de Atena (1933) pautou-se pela avaliação da experiência de mais de trinta cidades dispersas no mundo - aspecto que lhe conferia um sentido universal ${ }^{15}$. Tal caráter assentava-se em dois postulados principais, quais sejam: o reconhecimento de que a combinação de fatores políticos, sociais e econômicos pudesse alterar os destinos das cidades; a ênfase na positividade da arquitetura e do urbanismo como fator de mudança, capaz de promover o re-ordenamento das cidades, a saúde física e mental do indivíduo ou da coletividade ${ }^{16}$.

No contexto da valorização do potencial da arquitetura, da planificação (como definidores da forma da cidade) e da crença nas qualidades redentoras do desenho, consideradas capazes de promover a solução dos problemas citadinos, a arte urbana seria compreendida não apenas como um marco identitário, mas, principalmente, como expressão criativa coletiva. Por essa via, depreendemos que o processo criativo da arte pública entrelaça-se à construção da própria memória urbana. Contudo, tal memória não se restringe apenas a inserção de obras de arte nesse âmbito. Como destaca Peter Burke, "em diferentes países, as pessoas têm maneiras diferentes de relembrar o passado" e de vivenciar a cidade. Para os britânicos, a alegoria da continuidade parece particularmente 
cara, para os franceses o mito da revolução apresenta-se mais adequado para disparar o 'gatilho' da memória oficial. Por outro lado, como assinala o autor, "cidades ou países inteiros podem ser batizados ou rebatizados em honra de personagens famosos" ${ }^{17}$.

Não obstante, um impasse se coloca para a presente reflexão: como podemos apreender as representações da memória urbana por meio da análise da arte pública em cidades contemporâneas como Maringá, cujo perfil se caracteriza pela contínua busca da modernização, muitas vezes, alcançada à custa de constantes transformações dos espaços e da arquitetura, bem como, dos próprios modos de viver a urbe?

\section{PAISAGENS, PATRIMÔNIOS E IDENTIDADES CULTURAIS.}

Uma arqueologia histórica das cidades, inclusive das urbes contemporâneas, permite leituras diferenciadas da questão supracitada. Os referenciais político-sociais e a cultura material impregnados nos monumentos históricos, nas designações do espaço e nos vestígios arqueológicos retém códigos utilizados pelos sujeitos ou atores sociais para produzir significado e materializam acepções como identidade nacional e diferença étnica. Outras memórias manifestas por meio dos modos de habitar e da expressão artística também condensam referenciais identitários. Nessa direção, consideramos oportuno lembrar que a interpretação da cultura material pode possibilitar o acesso às vozes silenciadas das pessoas comuns em seus cotidianos e como assevera Pedro Paulo A. Funari, investigações dessa natureza, não raro, viabilizam a retomada de histórias que sucumbiram às versões da História oficial ${ }^{18}$.

De uma forma geral, o conceito de identidade define o que diferencia uns indivíduos dos outros, o que os caracteriza como pessoa ou como grupo social. Lembramos, no entanto, que o conceito de "identidade" aqui mencionado fundamenta-se na noção de "identidade cultural", ou seja, na definição do conjunto de relações, crenças, valores e motivações existentes no centro de toda a cultura que produz laços sociais, importantes para o fortalecimento do caráter local dos territórios para que sobrevivam ao mercado globalizado ${ }^{19}$.

As assertivas de Stuart Hall ${ }^{20}$ nesse campo também contribuem para uma melhor compreensão das relações entre arte pública, patrimônio e identidade, na medida em que o autor reconhece que os contornos da identidade surgem ditados pelas condições sociais determinadas pela 'vida material', mas adquire visualidade a partir do conjunto de papéis desempenhados pelo homem em sociedade. Esse conceito, no entanto, não se apresenta estático, muito pelo contrário, é passível de alterações decorrentes das mudanças nas formas como os sujeitos sociais são interpelados ou representados no mundo moderno, o que em última ins- 
tância demanda reconhecer a existência de identidades, no plural ${ }^{21}$.Se for coerente afirmar, como salienta Hall ${ }^{22}$, que o próprio conceito de identidade resulta de uma construção história, não constituindo uma herança natural ou genética, podemos inferir como sustenta Roger Chartier ${ }^{23}$ que as práticas culturais (inclusive as manifestações artísticas), expressas por meio de representações também o são. Arraigada, portanto, às esferas da cultura e do imaginário humano, o estudo das identidades culturais possibilita a percepção das relações com o passado que, por sua vez, permitem aflorar o sentido de pertencimento de indivíduos ou grupos às culturas nacionais ou locais. As associações entre o espaço e as identidades expressas nos bens culturais dos habitantes de Maringá, particularmente, nos conjuntos escultóricos e nos discursos plásticos apontam nessa direção.

Além disso, ratificamos que as imagens da cidade e sua população escultórica apresentam sinais evidentes dos embates sociais, dos signos da cultura material urbana, das permanências e rupturas de tempos vividos pelos habitantes da cidade e até aspectos que se circunscrevem às relações entre o espaço público e o privado. Não por acaso, a competitividade manifesta na sociedade contemporânea precipita-se sobre a expressão social do espaço, delimitando-o e hierarquizando-o por meio da valoração do solo, de medidas higienizadoras, da estetização iconográfica, da morfologia da cidade. A organização dos espaços livres e dos bairros da cidade corresponde a escolhas realizadas no decorrer dos processos de urbanização, exprime visões de mundo, e ainda, histórias e memórias que se deseja perpetuar. Em Maringá, situada no Estado do Paraná, criou-se uma série de representações que remetem aos mitos fundadores da cidade e sua vocação para um futuro promissor. A alusão à coragem dos primeiros habitantes dessa localidade se converteu em pretesias monumentais ${ }^{24}$. Esculturas e murais implantados em espaços públicos abertos ou fechados, a atribuição de nomes para as ruas, praças e edifícios da cidade reverenciam ocasiões e personagens de tempos pretéritos, além de contribuir para construção de uma dada memória da ocupação local. Esse é o caso das homenagens prestadas às figuras consideradas ilustres no Estado ou na cidade como Parigot de Souza, Manuel Ribas, Luis Teixeira Mendes, Pioneiro José Tel, entre tantos outros.

Aliás, Reginaldo B. Dias, assinala que "a combinação de diferentes formas de reprodução, fatos e personagens históricos, quando convertidos em nomes de ruas, podem se incorporar à vida cotidiana dos cidadãos". Sob essa ótica, acrescenta: "a despeito de eventuais limitações, a tendência de buscar perenizar nomes e eventos, longe de ser hábito desta ou daquela localidade, pode ser verificada em qualquer lugar do mundo e é adotada por governos de ideologias diversas" ${ }^{25}$.

Em Maringá a denominação de vias públicas e praças são atinentes ao planejamento urbano que ensejou a fundação da própria cidade. O "batismo" 
desses espaços obedece, desde a idealização dos primeiros bairros da cidade (na década de 1950) até a inauguração dos mais recentes, a certa lógica temática e critérios de proeminência. Alguns são dedicados aos nomes dos estados brasileiros, outros aos marcos da história política nacional ou aos membros da Companhia Melhoramentos Norte do Paraná (CMNP) ${ }^{26}$ que participaram do loteamento e a venda de terras na região. Todavia, em contraste com os temas previamente definidos para determinados bairros, notamos a inclusão de protestos de veneração às autoridades municipais (ex-prefeitos, ex-vereadores, ex-governadores) e aos 'pioneiros' que não abraçaram a carreira política - aspecto que evidencia exceções às regras definidas para a nomeação de ruas ou avenidas pelas autoridades municipais (vereadores).

Trata-se, segundo Dias e Pelegrini ${ }^{27}$, de um procedimento alimentado pela tradição de cultuar os chamados desbravadores tomados como personagens referenciais da história oficial da cidade, prática motivada pela Associação dos Pioneiros de Maringá ou por iniciativas isoladas de familiares de antigos moradores. Assim, detectamos a inserção desregrada de nomes dos fundadores da cidade nas vias públicas, a criação de um bairro inteiro dedicado a eles, como é o caso do Jardim São Silvestre, e ainda, a inserção de monumentos em celebração a esses personagens em diversas áreas da cidade.

A reverência a essa memória coletiva pode ser percebida também por meio da contemplação de alguns bens culturais expressivos do ponto de vista da identidade dos moradores da cidade de Maringá. Como? Palmilhando-se os "espaços" concebidos para fruição dos habitantes, as relações e as práticas sociais que nele tiveram lugar. Aliás, a configuração de algumas áreas da cidade apresenta marcos nítidos de uma dada memória e registros históricos concretos pela sua significação individual e coletiva. Tais elementos acabam se convertendo em motivos de discursos plásticos que não só tematizam os lugares da cidade e sua conformação, mas se impõem como suportes da memória coletiva dos segmentos sociais que coabitam essa urbe.

Fundada há pouco mais de meio século pela companhia de terras CMNP, Maringá vem crescendo, desde 1947, sob o signo do novo e da busca pela modernização. Essa perspectiva aberta ao futuro conferida à cidade certamente recebeu uma tradução plástica precisa, manifesta na instalação da arte pública e na racionalidade do seu planejamento urbanístico. A projeção de amplas vias de acesso, ruas largas, bulevares, praças e bosques reforçaram desde a formação da cidade sua inclinação para o progresso, escamoteando os ecos da degradação ambiental e os custos sociais da ocupação.

A inserção paulatina de bustos e placas em respeito as mais diversas figuras emblemáticas, a constante atualização das técnicas construtivas empregadas 
em projetos arquitetônicos arrojados, a contínua remodelação das praças, a verticalização dos edifícios e a criação do chamado "novo centro" tendem a colocar a imagem citadina de Maringá a par do que acontece nas grandes metrópoles mundiais, provocando certo esvaziamento do contraste entre as imagens do presente e do passado.

As transformações pelas quais tem passado essa cidade tornam relevantes a apreensão das memórias e múltiplas identidades cristalizadas na arte pública instalada em seus inúmeros espaços abertos. As diferentes maneiras de fruição desse patrimônio cultural (artístico e paisagístico) reportam às origens dessa população, implicam a transmissão de conhecimentos, o exercício de sociabilidades e a projeção de um futuro promissor.A visibilidade das imagens expostas nos espaços abertos imprime aos observadores, sejam eles habitantes ou transeuntes ocasionais, uma dada leitura da cidade que lhes sugere a apreensão de marcos históricos e das memórias urbanas. As efemérides citadinas também tendem a reforçar ou a reavivar a lembrança dos moradores da cidade por intermédio da celebração de datas especiais, da homenagem a figuras políticas ou intelectuais consideradas importantes no processo de engendramento da municipalidade. Tais formas de produção da memória social maringaense permitem a preservação de bens culturais cujo significado, embora forjado como representação coletiva, se restringe aos signos identitários das elites locais.

Guardadas as devidas proporções, nas mais diversas cidades do planeta notamos alusões às famílias ilustres locais e aos acontecimentos que, geralmente, se remetem às memórias de embates vitoriosos, representadas em diversas produções artísticas que constituem marcos de determinados períodos e enfoques da história humana. No caso de Maringá, as referências à figura dos primeiros moradores, denominados 'pioneiros', tendem a suplantar as diferenças e estabelecer um elo de cumplicidade entre os representantes da comunidade local. Parte da literatura que trata da história de Maringá corrobora com o discurso valorativo do perfil empresarial da companhia "colonizadora" CMNP e do arrojo dos 'pioneiros' que atuaram contiguamente às ações que conduziram à constituição da cidade ${ }^{28}$. No entanto, o sucesso do empreendimento de tais 'heróis' decorreu das intrínsecas relações que estes estabeleceram com essa companhia de terras que, por sua vez, foi favorecida pelo poder público mediante concessões a preços irrisórios ${ }^{29}$. Aos demais trabalhadores que se embrenharam na mata e desbravaram áreas inóspitas restou apenas o acesso ao mínimo necessário à sobrevivência - a eles foi reservado o esquecimento.

Em síntese, percebemos o espaço citadino como cenário de distintas formas de se preservar a memória social ou a memória coletiva ${ }^{30}$.Contudo, a morfologia e o panorama urbano podem explicitar formas diferenciadas de se enten- 
der as singularidades do próprio processo histórico e social de distintas áreas do globo terrestre. Se nos remetermos a algumas particularidades das cidades brasileiras nos defrontaremos com nomes de ruas, praças, parques e galerias que recriam e representam imagens da história nacional, eternizando eventos, personagens políticos e intelectuais. Mas, em alguns recônditos do país, os mais distantes, surgem referências identitárias locais, lado a lado, as menções de personagens fictícios da literatura, elementos da fauna e da flora, figuras políticas e intelectuais, ou meras referências à integração nacional. Se tais desígnios aparentemente prosaicos estão longe de preferências ocasionais, como afirma Peter Burke $^{31}$, uma análise detida das apropriações dos nomes e dos próprios espaços públicos nos permite apreender outros significados da paisagem urbana, trazendo a luz, múltiplos sentidos de pertencimento local.

\section{LEITURAS DA CIDADE E DA MEMÓRIA HISTÓRICA MARIN- GAENSE.}

A compreensão do significado dos espaços públicos de Maringá e de sua relação com a memória da ocupação implica o reconhecimento dos contextos nos quais essas obras foram criadas. Não obstante, a análise da materialidade das imagens iconográficas que lhe foram acrescentadas permite a percepção de temas que foram cultuados. Nessa direção, constatamos que a investigação sobre a intencionalidade da produção plástica e suas escolhas estéticas indica pretensões políticas, jogos de interesse social e pressões culturais relacionadas à concepção que os gestores, os administradores e demais habitantes imputaram a cidade.

Sem dúvida, os espaços livres da cidade de Maringá, projetados por Jorge Macedo de Vieira, denotam a perspectiva do seu uso social, mas não dissimulam o funcionalismo que informou sua criação, nem tampouco, a concepção das fronteiras físicas dos distintos zoneamentos da cidade. Nessa urbe, como em várias outras localidades brasileiras, cabe ao poder público atinar sobre as demandas da arte no espaço citadino, muitas vezes reduzida ou associada apenas aos tributos concretizados por intermédio de símbolos cívicos, torsos ou placas. Tornam-se corriqueiras as instalações de monumentos, painéis e esculturas de artesãos locais nos espaços abertos, em edificações públicas ou construções privadas.

O conjunto da população escultórica dispersa nos espaços públicos de Maringá insere-se num circuito de preitos que elegeram desde políticos, artistas e personalidades locais até expoentes da história nacional. Entre eles, destacamse placas e bustos dedicados a Nagibe Name (instalado na esquina da Avenida XV de Novembro com Duque de Caxias), Joubert de Carvalho ${ }^{32}$ (na Praça Raposo Tavares - antigo terminal rodoviário), Napoleão Moreira da Silva ${ }^{33}$ (na praça com o mesmo nome), Ary de Lima (na Praça Kennedy), Melwins Jones (na 
Praça dos Sertões), Calil Haddad (no teatro com mesmo nome), Tiradentes (na Praça Manoel Ribas), Duque de Caxias ${ }^{34}$ (na Av. Itororó - defronte da Loja Maçônica), Dr. Annibal Bianchine da Rocha - considerado o "jardineiro" de Maringá (na Praça Sete de Setembro).

Devemos registrar também a projeção da Praça Zumbi dos Palmares, localizada no Bairro Santa Felicidade - um dos mais carentes da cidade. Essa área foi criada como iniciativa da própria comunidade local, liderada por membros do Movimento Negro em Maringá e inaugurada na Semana da Consciência Negra, em 1999. A melhoria dos equipamentos urbanos e o reconhecimento da praça como patrimônio cultural do bairro conforma uma das principais reivindicações dos moradores, uma vez que esse espaço cumpre uma função social importante. É palco de atividades esportivas, políticas e culturais ${ }^{35}$.

A menção a acontecimentos relacionados à escravidão não constitui prerrogativa única do Bairro Santa Felicidade. Lideranças vinculadas ao abolicionismo foram contempladas na Zona 4, onde se situam as Ruas Joaquim Nabuco, Princesa Isabel, José do Patrocínio, entre outras. Mas, como adverte Dias, esse bairro não abriga a Avenida dos Palmares, principal via de acesso do Conjunto Liberdade (inaugurado na década de 1970), nem tampouco a Praça Zumbi supracitada. Tal fato, sem dúvida, é motivado pela emergência de distintos enfoques históricos:

A separação não é desprovida de sentido, já que a ligação desses fatos e personagens, embora relacionados à questão da escravidão, não é tão direta. A maioria dos movimentos de consciência negra prefere celebrar Palmares e Zumbi e criticar o 13 de maio e a Lei Áurea. Com o tempo o batismo de vias urbanas, tradicional território de sedimentação da história oficial, foi permeável à alusão a movimentos populares e seus protagonistas $^{36}$.

Com efeito, os tributos a determinados personagens históricos e a materialização do culto a eles, por intermédio da nomeação das vias públicas ou da arte pública, não se consubstancia apenas por meio da inserção da obra no espaço urbano. A arte pública só se integra ao espaço citadino quando a população residente se identifica com ela, quando os habitantes a percebem como elemento complementar da dinâmica urbana, estabelecendo uma afinidade positiva (talvez até afetuosa) ou meramente cordial com o monumento. Como revelam os especialistas, a presença da arte seja ela transitória ou edificada, em meio à paisagem de concreto da cidade contemporânea surge como inclusão terna e humanizadora do espaço ${ }^{37}$.

Curiosamente, em Maringá, esta assimilação da arte pública surge de maneira multifacetada, a começar pelos monumentos instalados nas suas principais 
vias de acesso. As placas de concreto armado em formato de notas musicais estilizadas na Avenida Colombo, cuja concepção foi formulada a partir de uma alusão a canção de Joubert de Carvalho - letra que teria inspirado o nome da cidade é um exemplo a ser pensado. Enquanto, uma das gigantescas notas ostenta a saudação "Seja bem-vindo", a outra abriga o próprio nome da cidade. Porém, os depoimentos da população que constam da revista Tradição ${ }^{38}$ apontam para o fato de que os próprios moradores da região têm dificuldade de reconhecer o formato das notas musicais do monumento e de interpretar a simbologia expressa nessas placas.

Em contrapartida, a Catedral Basílica Menor de Nossa Senhora da Glória, edificada na área central da cidade, contempla o maior símbolo da cidade e parece desempenhar seu duplo desígnio: o de monumento e de arte pública. Projetada pelo arquiteto José Augusto Belucci, a igreja foi construída entre meados de 1959 e 1972, se mantém inscrita como prioridade no circuito turístico da cidade. A sua arquitetura moderna erguida em concreto aparente e suas formas arrojadas conferem ao monumento um valor artístico representativo. A edificação, segundo a Cúria Metropolitana, é o primeiro monumento em altura na América do Sul e o décimo no âmbito mundial, e ainda, conta com a pedra fundamental em mármore, retirado das escavações da Basílica de São Pedro, no Vaticano ${ }^{39}$.

A Praça da Catedral re-inaugurada na década de setenta, talvez seja a mais conhecida da cidade. Trata-se de uma área muito bem equipada, arborizada e iluminada. O gramado no entorno da igreja convida os turistas e habitantes locais a utilizarem a praça para brincadeiras e jogos informais nos feriados e finais de semanas. O seu amplo estacionamento é intensamente utilizado tanto pelos adeptos do culto católico, quanto pelos usuários da praça que aproveitam também os bancos ao redor dos espelhos d'água e das fontes luminosas para usufruir o ar mais fresco, além de apreciarem a paisagem. A sedutora composição paisagística sugere um ambiente capaz de integrar os ares de modernidade da monumental catedral, os maços de palmeiras e demais espécies da vegetação ao seu redor. Esse monumento integra-se ao cotidiano do cidadão maringaense que usufrui do seu espaço e sua beleza. A população residente avista o cone central da catedral a partir de diversos pontos da cidade. Cartões postais, campanhas publicitárias e logotipos de empresas sediadas em Maringá exploram o designer da construção religiosa.

De fronte à Praça da Catedral, numa esplanada de concreto, nos deparamos com um outro espaço aberto voltado para a sociabilidade da população local que desperta o interesse dos turistas que visitam a cidade. Essa área equipada com inúmeros bancos e um palco ao ar livre destinado ao uso da comunidade, também foi projetada por Belucci, em 1985, durante a administração do Prefeito 
João Paulino Vieira Filho. Esse espaço está diretamente vinculado à dinâmica administrativa, pois abriga de um lado, o prédio do Fórum e a Agência Central dos Correios, e do outro, o Paço Municipal e o Hotel Bandeirantes - exemplar da arquitetura moderna em Maringá, reconhecido como patrimônio cultural da cidade.

Na primeira gestão do alcaide Said Felício Ferreira, esta praça foi completamente modificada e pavimentada com cerâmica e, a partir de então, passou a ser conhecida como Centro de Convivência Comunitária Renato Celidônio, destinada às celebrações de cunho social e filantrópico. Foi assim nomeada em tributo à popularidade do deputado federal, cujo mandato se circunscreveu ao período de 1962 a 1966. Ele inseriu Maringá no circuito do Festival do Cinema Nacional (em maio de 1958) - algo lembrado pela população com certo saudosismo. Esse político se tornou membro-fundador de um dos clubes mais tradicionais da cidade - o Maringá Clube ${ }^{40}$.

A remodelação da praça, segundo o engenheiro Gilmar Ferdinandi ${ }^{41}$, ocorreu em função de que guardava características não condizentes com "as modernas construções que surgiram (...) ao seu redor" nos anos oitenta e, em decorrência, de que embora localizada entre dois símbolos do poder - a Catedral e a Prefeitura - vinha sendo considerada "ponto de encontro de prostitutas e desocupados". Além disso, havia a disposição de "devolver à praça a nostalgia que a cercava no início dos anos 70, quando inúmeros jovens a invadiam depois da matinê do cine Maringá" ${ }^{42}$.

O Centro Comunitário acolhe vários exemplares de arte pública. Defronte ao prédio dos Correios, há um monumento religioso consagrado a Bíblia: duas lajes representando um livro aberto apresentam os "Dez mandamentos da Lei de Deus". Em frente ao Paço Municipal noutro lado da mesma praça foi erguido um marco dedicado à Kakogawa (Japão) e Leiria (Portugal), cidades consideradas co-irmãs de Maringá. Devemos destacar que essa área abriga na sua entrada principal, o obelisco da cidade, cuja direção aponta para o cume da torre da Catedral. Inaugurado em 22 de novembro de 1987, com a presença do governador Álvaro Dias ${ }^{43}$, o obelisco (com proporções bem mais acanhadas do que a Catedral) foi carinhosamente apelidado pela população como "Bicudo" ${ }^{44}$. Desde então, o monumento em concreto vem recebendo crianças e jovens que se arriscam a deslizar sobre sua rampa frontal, mesmo sem a permissão dos vigilantes guardas municipais.

O 'zelo' das autoridades administrativas motivou a criação de uma central de monitoramento dos vigias municipais no Centro de Convivência Comunitária, visando a inibir práticas consideradas nefastas para Maringá, como a 'vadiagem' e o fluxo de 'desocupados, viciados e marginais' nas cercanias do obelisco. Esse 
procedimento foi alvo de destacada nota publicada em outubro de 2005, pelo $O$ Diário do Norte do Paraná, um dos jornais de maior tiragem na região ${ }^{45}$. A referida nota apresenta entrevistas com moradores e indica que a assepsia realizada no local (e em quase toda a área central) contou com a aprovação da população que freqüenta ou reside nessas adjacências. A prática de excluir do convívio social pessoas tidas como 'indesejáveis' é muito comum no mundo ocidental desde os anos finais do século XVIII ${ }^{46}$.

No caso de Maringá, tentativas dessa natureza evidenciam o intuito de não se macular a "aura" do progresso e da modernidade cunhada na imagem da cidade desde a sua fundação. $\mathrm{O}$ zoneamento urbano projetado desde meados da década de 1940 previa a cristalização de espaços distintos destinados às elites e aos trabalhadores, às atividades comerciais, agrícolas e industriais. A separação dos corpos no município expressa a divisão hierarquizada dos espaços e a distinção dos lugares da cidade.

Mas, a despeito do planejamento urbano projetado por Jorge Macedo, desafortunadamente, o obelisco, por vezes, passa despercebido pelas multidões que usufruem da praça e de seu entorno. Por ocasião dos eventos agenciados pelas associações beneméritas ou pela própria administração pública, como a "Festa das Nações", a "Festa das Flores" e outras comemorações municipais, o monumento acaba sendo encoberto por barracas de comidas típicas ou palanques improvisados.

Como podemos observar nessa fotografia há uma justaposição entre esses monumentos, dispostos na mesma direção. Mas, curiosamente a concepção do Obelisco do calçadão tem sido ratificada, ora como um monumento em homenagem aos artistas maringaenses ${ }^{47}$, ora como um "símbolo da caminhada para o infinito" ou "uma forma moderna de seta", indicando a suposta "vocação" da cidade para a "paz" ${ }^{48}$.

O 'Monumento ao Desbravador', inaugurado em 1972, na Praça Sete de Setembro, chama-nos especial atenção, pois apresenta características diversas dos conjuntos escultóricos supracitados, apesar da recorrência à verticalidade.

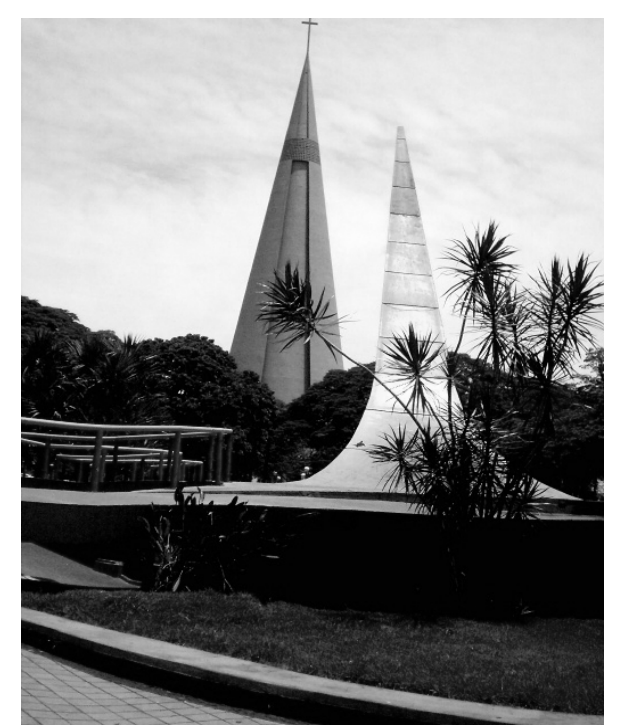

Imagem 1 - Obelisco e Torre da Catedral ao fundo - Vista do Centro de Convivência Comunitária Renato Celidônio. Foto: Sandra Pelegrini. 
Localizado numa área de com $3.052 \mathrm{~m}^{2}$, a escultura foi instalada na rotatória cuja função inicial assegurou a interligação entre o chamado Maringá Velho e a Nova Maringá, traçada por Jorge Macedo de Vieira ${ }^{49}$. Os depoimentos de autoridades e urbanistas denotam a perspectiva de se estabelecer um vínculo entre as duas áreas. Mas o significado simbólico da obra estimulou, desde os anos finais da década de 1960 e inícios dos anos setenta, a projeção de uma memória social calcada na figura do 'pioneiro', tomado aqui como alusão aos primeiros habitantes da cidade ${ }^{50}$.

Destarte, o escultor Henrique de Aragão foi convidado pela municipalidade para confeccionar um monumento à altura da 'bravura' e do 'desprendimento' dos primeiros moradores da região. Para tanto, projetou uma escultura com 7,10 $\mathrm{m}$ de altura e $980 \mathrm{~kg}$ a partir da utilização de um emaranhado de fios de aço recobertos de cobre. Ao lado da escultura foram confeccionados em concreto aparente, três machados estilizados. $\mathrm{O}$ conjunto tende a associar à imagem dos desbravadores a eficácia do trabalho, reforçando-lhes o determinismo e a coragem que transformou a região em uma área promissora. Segundo o seu criador, Henrique Aragão, a nudez da escultura representa a 'singeleza do pioneiro' e a 'força de seu espírito empreendedor'. Tão alto e tão forte quanto o pinheiro do Paraná, propagado nos versos, prosas e memórias da ocupação do Estado, a postura esguia e as mãos estendidas para o alto parecem projetar o empreendedorismo dos primeiros habitantes de Maringá e suas utopias.

Na mesma praça, também foi incluída uma placa em pretesia a um dos moradores mais antigos da cidade e considerado responsável pelo plantio de inúmeras espécies de árvores nas ruas e praças da cidade. A ele foram dedicadas as inscrições, instaladas nas proximidades dos bancos: "Ao Dr. Annibal Bianchine da Rocha, por sua constante e dedicada colaboração no setor de parques e jardins, homenagem do povo de Maringá. 1972 - Ano do Jubileu de Prata”.

Re-urbanizada e entregue para a comunidade maringaense em 9 de maio de 1988, a praça passou por um processo de reformulação que incluiu a inserção de novas mudas de flores, árvores e arbustos. Além disso, se inseriu num rol de medidas tomadas pela municipalidade tendo em vista a reconstituição da história da cidade ${ }^{51}$.

A expressão artística do 'Monumento ao Desbravador', sem dúvida, surge vinculada à construção de determinada memória social urbana. Aninha Calijuri, uma das primeiras moradoras da região, ao interpretar poeticamente a obra de arte, assinala:

Na Praça Sete de Setembro, do Maringá Velho, o monumento artístico - o Pioneiro Maringaense, criado pelas mãos do artista Aragão, acaricia os nossos bosques, as nossas flores, na 
harmonia de suas linhas espiritualizadas. O Pioneiro Maringaense, com os braços levantados aos céus, agradece a terra sagrada que ampara os nossos pés. E no silêncio grandioso, que emana do nosso planeta, a Praça Sete de Setembro envolve na sua radiosa aura, o nosso viver de todos os dias ${ }^{52}$.

O valor simbólico da homenagem prestada aos pioneiros por meio dessa escultura devotada à construção da memória social local e inserida numa praça que reverencia um marco igualmente significativo da história nacional (a data da independência do Brasil), parece atingir apenas a afetuosidade de uma pequena parcela da população. Se os objetivos daqueles que conceberam a inserção desse monumento em um espaço tão destacado da cidade centravam-se na idéia de forjar certa identidade maringaense, talvez tenham se frustrado.

Aparentemente indiferente ao solene tributo, a maior parte da população residente ao não se identificar com o referido monumento aos chamados 'pioneiros' ou 'desbravadores dos sertões paranaenses' acabou atribuindo-lhe outro significado. Rebatizaram popularmente o local como 'Praça do Peladão' e, em distintos momentos, alguns habitantes se apropriaram da obra com intentos igualmente diversificados. Recentemente, o corpo desnudo do pioneiro - alvo de discussão e debate à época de sua confecção, amanheceu uniformizado com as cores do Galo Maringá - time de futebol que subiu para Primeira Divisão do Campeonato Paranaense, em 2006. A matéria "Símbolo de Maringá 'veste` camisa do time", redigida por Cláudio Viola, publicada no jornal $O$ Diário do Norte do Paraná, em novembro de $2005^{53}$, não só anunciou que a referida escultura foi brindada com o uniforme do referido time, como destacou o apoio dos transeuntes à iniciativa da torcida organizada. Situações similares ocorram em ocasiões comemorativas dos títulos do Grêmio de Esportes Maringá.

Cabe-nos lembrar que a nudez absoluta da escultura gerou debate acalorado entre políticos, religiosos, artistas e a população à época da inauguração (1972). Após muitas celeumas, o artista foi convencido a "cobrir as vergonhas" da escultura com uma folha de parreira. Aliás, essa solução estética vem sendo utilizada de maneira compulsória desde longa data, e em especial, pelos artistas renascentistas. O alarido e a solução encontrada para a questão sinalizam o "rigor moral" da sociedade maringaense nos anos setenta.

Monumentos construídos em escalas menores parecem passar despercebidos da população local. Esse é o caso dos bustos e esculturas instaladas nas praças Manoel Ribas $\left(10.568 \mathrm{~m}^{2}\right)$ e Presidente Kennedy $\left(2.307,21 \mathrm{~m}^{2}\right)$. Localizadas em áreas centrais da cidade, essas praças têm em comum a mesma tipologia, pois foram concebidas como rotatórias que articulam vias de trânsito intenso. Contudo, apresentam equipamentos urbanos e estruturas de lazer esportivo, con- 
cha acústica e mesas para jogos ou lanches que viabilizam maior fruição do espaço público. Na Praça Manuel Ribas, o busto de Tiradentes foi instalado sob os auspícios da Loja Maçônica de Maringá e inaugurado durante a segunda gestão do prefeito Said Felício Ferreira, em 15 de novembro de $1996{ }^{54}$.

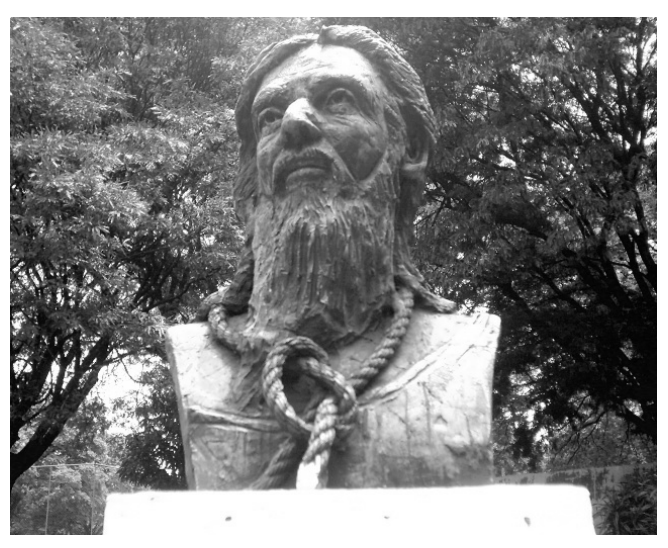

Imagem n. 2 - Busto de Tiradentes Praça Manuel Ribas

Foto: Sandra Pelegrini

No pedestal dessa escultura, encontramos uma placa que reverencia a figura do Alferes Joaquim José da Silva Xaxier como 'patrono cívico nacional' e 'protomátir da independência'. Essa praça está inscrita no 'circuito das atrações noturnas' dos jovens de toda a cidade. Outras duas obras de arte também significativas pelas características estéticas que apresentam podem ser encontradas na Praça Presidente Kennedy (situada na Zona 01) e na Praça do Lions (Zona 4). Trata-se, respectivamente, de tributos ao professor Ary de Lima, autor do hino da cidade de Maringá e

a Melwin Jones, fundador do Lions Club Internacional. Embora a primeira praça tenha sido construída em 1983, pela empresa Rivesa Ribeiro Veículos, o monumento e demais equipamentos foram instalados somente em 1999. A segunda foi inaugurada em abril de $1992^{55}$. A estatutária presente nesses lugares da cidade, mais uma vez, apontam vínculos com a história oficial local e universal, bem como, vestígios de princípios humanitários fomentados por associações como é o caso do Lions Club de Maringá.

Além das esculturas e monumentos que de alguma forma se reportam predominantemente aos personagens que contribuíram para o crescimento da cidade, diversas produções artísticas integrantes da paisagem urbana de Maringá fazem alusão ao processo de ocupação no Norte do Paraná, reforçando os ícones signatários da ousadia dos "desbravadores" que velozmente transformaram a mata fechada em uma cidade moderna. A abundante paisagem calcada em concreto armado e o verde das frondosas árvores são elementos plásticos recorrentes nas composições pictóricas que tematizam a qualidade de vida e a constante modernização de Maringá. 


\section{OUTRAS LinguAgens E VERSÕES DA ARTE PÚBLICA.}

A monumentalidade da Catedral e o gigantismo da figura do desbravador surgem como elementos compositivos marcantes em manifestações artísticas locais confeccionadas com os mais variados materiais, estilos e técnicas. Esse é o caso do mosaico concebido por Poty Lazzaroto, em 1997, para uma das paredes internas do saguão do Teatro Municipal Calil Hadad, das pinturas murais realizadas por Zanzal Matar na fachada principal de estabelecimentos comerciais como o "Supermercado Atacadão" e do "Hotel Cidade Verde", do mural em cimento e cola de Eder Porttalha edificado numa das fachadas laterais do Colégio Santa Cruz, situado à Rua Antônio Octávio Scramim (ao lado da Escola Estadual José Gerardo Braga) ${ }^{56}$.

A saga dos primeiros habitantes é destacada de maneira contundente no mural de Eder Portalha. As formas em alto relevo e a narrativa cadenciada do processo de ocupação da região são minuciosamente exploradas pelo artista. $\mathrm{O}$ desmatamento, o esforço da chegada, a construção das primeiras casas e o árduo trabalho da lavoura destacados pelo artista constituem motivos de orgulho dos pioneiros ${ }^{57}$.

Como podemos notar, mais uma vez a monumentalidade da obra (dimensões $13 \times 5 \mathrm{~ms}$ ), somada a representação da terra próspera, do intenso labor e da veloz modernidade alcançada pela cidade potencializam as ações daqueles que enveredaram pelos sertões do Paraná e os transformaram em áreas prósperas. $\mathrm{Na}$ imagem $\mathrm{n}^{\circ} 4$, notamos a representação da mulher grávida, uma alusão à idéia de futuro e do investimento dos

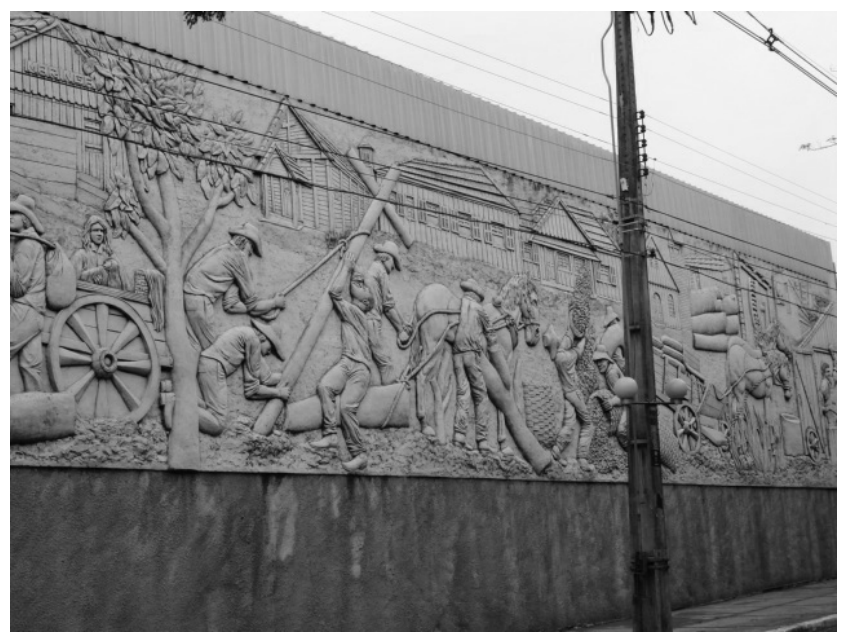

Imagem n. 3 - Mural: Eder Portalha.

Foto: Sandra Pelegrini. pioneiros (as) que se dirigiram para Maringá com o propósito de trabalhar e progredir.

A fase áurea do cultivo do café e a altivez dos agricultores também foram contempladas pelo artista, um dos poucos que tematizaram a participação das 


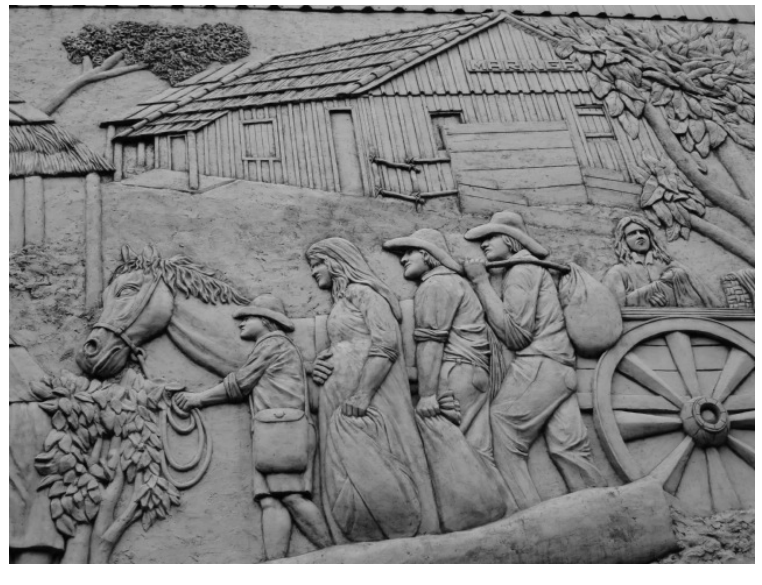

Imagem n. 4 - Mural: Eder Portalha - Detalhe da chegada dos primeiros moradores Foto: Sandra Pelegrini.

'pioneiras', pois elas também trabalhavam na cultura do café, nas roças domésticas, alimentação dos animais, educação das crianças e demais atividades que lhes eram impostas.

A observação atenta da arte instalada nos espaços públicos de Maringá permite a percepção de um discurso plástico que tende a enaltecer determinados personagens e edificar uma dada memória social do processo de ocupação que, em última instância, também implica cotejar as dimensões das experiências vivenciadas na cidade.

\section{CONSIDERAÇÕES FINAIS.}

Se for válido detectarmos a assimilação de atitudes universais na estratégia de preencher os espaços públicos com esculturas ou nomear as vias urbanas como tributos aos personagens da história oficial, torna-se imperioso reconhecermos que tais práticas se justapõem às vivências da população local. Nessa mulheres no processo de ocupação. Embora, as representações tenham se restringido ao enfoque da labuta doméstica e a procriação, o movimento impresso nas figuras femininas apontam a importância do seu trabalho, a agilidade e o empenho necessários na organização das tarefas, como evidenciamos na imagem $n^{\circ} 5$.

Cabe-nos lembrar que, do ponto de vista das primeiras moradoras, tais imagens ainda não fazem jus a participação das

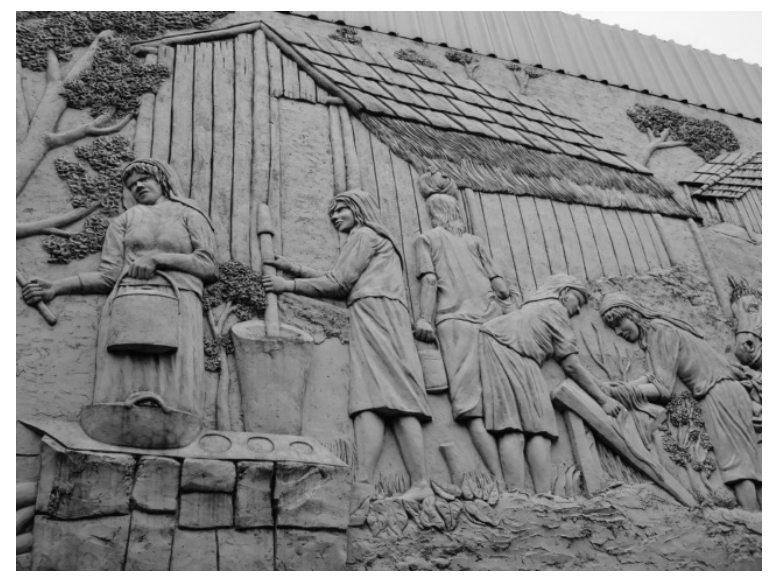

Imagem n. 5 - Mural: Eder Portalha - Destaque ao trabalho doméstico exercido pelas mulheres - Foto: Sandra Pelegrini. 
direção, consideramos basilar admitirmos que se algumas manifestações artísticas instaladas em distintos lugares da cidade integram o cotidiano da população e a dinâmica da paisagem citadina, outras parecem passar despercebidas por parte dos habitantes da cidade.

De todo modo, detectamos que determinados locais não cumprem a função social para qual foram projetados, especialmente, como lugares de permanência capazes de estimular o desenvolvimento de atividades culturais, religiosas e políticas, de preservação de costumes e tradições locais. Mas, esta realidade se deve a uma série de problemas urbanísticos decorrentes do aumento da população e do volume do tráfego de veículos e pessoas, da violência crescente, da degradação progressiva do ecossistema urbano e da qualidade de vida na cidade.

Não podemos descuidar que algumas áreas da cidade, como por exemplo, as rotatórias foram criadas como eixos de articulação viária, visando resolver o fluxo intenso de veículos nos entornos das praças, aspecto que acabou comprometendo as possibilidades de uso pelos habitantes. Esse tipo de impedimento inibe a apropriação desses lugares pela população residente e também inviabiliza a sua identificação com os exemplares da arte pública instalados nesses locais.

As praças centrais (exceto as rotatórias), em sua maioria, configuram como lugares de passagem ou espaços de articulação do fluxo de pedestres, recebendo uso intenso somente durante o dia. No extremo oposto, algumas praças localizadas nos bairros residenciais, embora pouco aproveitadas como espaços de inserção da arte pública, geralmente, são desfrutados com regularidade pelos moradores das imediações que utilizam essas áreas como lugar de permanência e lazer. Esse é o caso da Praça Zumbi. Ao apropriar-se desses espaços, a comunidade assimila o sentido de pertencimento e se interessa em mantê-los em bom estado de conservação $0^{58}$.

A cidade de Maringá, desde seu plano original, desenhado pelo urbanista Jorge de Macedo Vieira, contava com um grande número de praças. Tal concepção foi inicialmente capaz de promover o equilíbrio, o crescimento urbano racional e ordenado e garantir qualidade de vida à maior parte da população residente. $\mathrm{O}$ aumento significativo da população, somado ao fato de que muitos espaços livres da cidade não cumprem a função social da praça, tampouco viabilizam a convivência e a sociabilidade dos habitantes citadinos. Embora acolham signos das memórias coletivas (e individuais) e referências da história nacional e local, essas áreas necessitam ser integradas ao circuito cultural da arte pública no seu sentido mais pleno. A premente reabilitação desses espaços pode garantir a permanência de códigos identitários aos bairros, ruas e até mesmo a própria urbe que carrega consigo a insígnia de "Cidade Verde". 
A análise dos elementos plásticos e dos espaços elencados nesse ensaio, em última instância, visou o estudo da historicidade urbana, mas, principalmente, a apreciação da paisagem citadina repleta de registros imagéticos relativos aos costumes e as histórias da população residente. Aspectos considerados pontos de partida para a percepção da arte pública como bens que devem ser incorporados, reconhecidos e preservados como patrimônio cultural maringaense.

Sem dúvida, arraigados às esferas da memória urbana, os referenciais identitários possibilitam a consolidação de relações com o passado que, por sua vez, permitem aflorar o sentido de pertencimento de indivíduos ou grupos às culturas locais, étnicas, religiosas. Sem a pretensão de esgotar o tema, lembramos que as associações entre o espaço, a arte pública e o patrimônio cultural de Maringá constituem importantes evidencias sobre a articulação entre as representações da modernização no imaginário e na produção da memória social local.

Recebido em 16 de junho de 2008

\section{NOTAS}

${ }^{1}$ Castells apresenta estudo detalhado sobre a construção histórica das identidades e das relações so ciais. Cf.CASTELLS, Manuel. 0 poder da identidade. A era da informação: economia, sociedade e cultura. Lisboa: Fundação C alouste Gulbenkian, 2003.

2 Essa conceituação do urbanismo fundamento u-se em LEFEBVRE, Henri. A Revolução U rbana. Belo Horizonte: UFMG, 1999, p.147.

${ }^{3}$ PALLAM IN , Vera M. Arte U rbana - São Paulo: região central (1945-1998). 1. ed. São Paulo: Annablume/Fapesp, 2000.

${ }^{4}$ BEN EVO LO, Leonardo. História da Cidade. São Paulo: Perspectiva, 1996; DE CERTEAU, Michel. "Relatos de Espaço" In: _._._. A invenção do cotidiano: artes de fazer. (2ª ed.). Petrópolis: Vozes, p. 1996, 199-217; FRAM PTO N, Kenneth. Arquitetura moderna. São Paulo: Martins Fontes, 2000.

${ }^{5}$ Cf. SAN TOS, C. F. A obra de arte e o espaço público. I Seminário de Arte Pública da Cidade de Florianópolis. Santa C atarina: Prefeitura Municipal de Florianópolis, 2003, p. 34.

${ }^{6}$ Cf. KN AUSS, Paulo. "Cidade Panteão: uma produção social da imaginária urbana" In: Sorriso da cidade: imagens urbanas e história política de N iterói. N iterói/R.J.: Fundação de Arte de N iterói, 2003, p. 179.

${ }^{7}$ AGUILHON, Maurice. Marianne au pouvoir. L'imagerie et la symbolique républicaines de 1880 a 1940. Paris: Flammarion, 1989; AGU ILHO N, Maurice. "La statuo manic et I'histoir" In: Histo ire vagabonde: etnologie e politique dans la France contemporaine. Paris: Gallimard, 1988; H ARG RO VE, June Ellen. Les statues de Paris: la représentation des grandes hommes dans les rues et sur les places. Paris: Albin Michel, 1989.

${ }^{8}$ Sobre as simbologias utilizadas pela República brasileira consultar: CARVALH O, José Murilo de. $A$ formação das almas. São Paulo: Companhia das Letras, 1990.

${ }^{9} \mathrm{~A}$ arte conceitual surgiu no século $\mathrm{XX}$, a partir de inúmeros experimentos que consideravam 0 conceito (ou a idéia central) de uma obra mais importante do que o seu resultado final. Para tanto, os artistas exploravam o uso de diferentes meios e linguagens para transmitir o significado de suas obras. 
$\mathrm{N}$ a década de sessenta essa forma de pensar a arte se difundiu dando origem a várias manifestações artísticas como a 0 p-Art, a Pop-Art, entre outros. A Pop-Art surgiu nos Estados U nidos da América, na década de 1960. Atingiu extensa repercussão internacio nal e, em termos estéticos, se ocupou do uso de imagens familiares, objetos e signos comuns ao cotidiano urbano. C f. GO M BRIC H, E. H. A H istória da Arte. Rio de Janeiro: LTC, 1999, p. 599-610; SMITH, Roberta. "A arte conceitual" In: STAN GOS, $\mathrm{N}$ ikos. Conceitos de arte moderna. Rio de Janeiro: Jorge Zahar , 2000, p.182-192.

${ }^{10}$ Sobre 0 assunto consultar: PALLAM IN , Vera M. Arte U rbana - São Paulo: região central (1945-1998), op. cit.; AMARAL, Aracy e TO RAL, André. Arte e sociedade no Brasil. V.1,2 e 3. São Paulo: Instituto Callis, 2005 e REIS FILH O, Daniel A. A paixão de uma utopia. Rio de Janeiro: Espaço e Tempo, 1988. ${ }^{11}$ BRESC IAN I, M aria Stella. Imagens da Cidade - Séculos XIX - XX. São Paulo: Anpuh/M arco Zero/ Fapesp, 1993.

120 realismo so cialista e o muralismo mexicano constituem exemplos marcantes da arte com enfo ques so ciais, franqueada para as massas.

${ }^{13}$ SAN TO S, C. F. A obra de arte e o espaço público, op. cit.

${ }^{14}$ C f. CH AU Í, Marilena. Convite à Filosofia. São Paulo: Ática, 1994, p. 125.

${ }^{15}$ Segundo a Carta de Atenas (1933), constam da lista das urbes analisadas pelos grupos organizados nesse congressos internacional, as cidades de Amsterdã, Atenas, Bruxelas, Baltimore, Bandoeng, Budapeste, Berlim, Barcelona, C harieroi, Colônia, D alat, D etroit, D essau, Frankfurt, G enebra, Gênova, Haia, Los Angeles, Litoria, Londres, Madri, O slo, Paris, Praga, Roma, Roterdã, Estocolmo, U trecht, Verona,Varsóvia, Zagreb e Zurique. As Cartas Patrimoniais encontram-se no site do Instituto do Patrimônio H istórico e Artístico N acio nal. D isponível em: < http://ww w.iphan.gov.br/legislac/cartaspatrimoniais/cartaspatrimoniais.htm>. Acesso em: jan. 2002.

${ }^{16}$ PELEG RIN I, Sandra C. A. 0 patrimônio cultural no discurso e na lei: trajetórias do debate sobre a preservação no Brasil. Patrimônio e Memória - Revista Eletrônica CED AP, v. 2, n. 2, p. 1-24. , Assis - São Paulo, 2006.

${ }^{17}$ Cf. BU RKE, Peter. A alma encantadora das ruas. Folha de S. Paulo, São Paulo, 31.07.2005, Caderno Mais, p. 3.

${ }^{18} \mathrm{Q}$ uestões relacionadas a essa problemática são comentadas em publicações como: FU N ARI, P.P. "Heterogeneidade e conflito na interpretação do Q uilombo dos Palmares" In: Revista de História Regional, v. 6 (1), p. 11-38, Ponta G rossa. 2001; FU N ARI, Pedro Paulo A. e FERREIRA, Lúcio Menezes. "C ultura material histórica e patrimônio" In: Primeira Versão. Campinas: IFCH/U nicamp, n. 120, 2003, p. 13-20; FU N ARI, P. P e PELEG RIN I, Sandra. C. A. Patrimônio Histórico e Cultural. Rio de Janeiro: Jorge Zahar, 2006.

${ }^{19} \mathrm{H}$ ALL, Stuart. A identidade cultural na pós-modernidade. Rio de Janeiro: D P\&A, 1999.

20 Id. Ibidem.

${ }^{21}$ FU N ARI, P. P. e PELEG RIN I, Sandra C. A. "C onciencia sobre la preservación y desafíos del patrimonio cultural en Brasil" In: PATIN O , D iógenes (org.) Las vías del Patrimoniol, la Memo ria y la Arqueología. Popayán/C olombia: Editorial de la U niversidad del Cauca, 2007, p. 33-56.

22 HALL, Stuart. A identidade cultural na pós-modernidade, op. cit.

${ }^{23}$ CH ARTIER, Roger. A história cultural. Rio de Janeiro: Bertrand Brasil, 1990.

${ }^{24}$ D esbravadores ou pio neiros são termos recorrentes utilizados pelos memorialistas lo cais para designar a natureza aventureira e aguerrida dos primeiros habitantes da região, pessoas que apesar de inúmeros infortúnios, se fixaram nessa área e desencadearam seu desenvolvimento.

${ }^{25}$ Cf. D IAS, Reginaldo Benedito. "A história além das placas: os nomes de ruas de Maringá (Pr) e a memória histórica" In: Revista Ensino de H istória, n. VI, Londrina, 2005, p. 35-36.

${ }^{26}$ A percepção da tônica do processo de ocupação promovido pela referida Companhia pode ser observada nos documentos produzidos pela pró pria CMN P, tais como: Companhia Melhoramentos N orte do Paraná: a maior empresa colonizadora da América do Sul. São Paulo: C M N P, 1957 e Colonização e desenvolvimento do Norte do Paraná. São Paulo: Publicação Comemorativa do Cinqüentenário da Companhia, 1975. 
${ }^{27}$ Esse assunto foi aprofundado pela autora no seguinte capítulo de livro: PELEG RIN I, Sandra C. A. "A paisagem urbana de Maringá expressa em distintas representações pictóricas da cidade" In: PELEG RIN I, Sandra C . A. \& ZAN IRATO , Silvia H. N arrativas da pós-modernidade na pesquisa histórica. Maringá: EDUEM, 2005 (p. 121-140).

${ }^{28}$ Referimo-nos aos trabalhos: LUZ, France. 0 fenômeno urbano numa zona pioneira: Maringá. MaringáPr: Prefeitura Municipal de Maringá, 1997 e AN DRADE NETO, A. de O. Maringá: ontem, hoje e amanhã. Maringá, 1979.

29 TO MAZI, N elson D. N orte do Paraná: Histórias e fantasmago rias. C uritiba: SCH-D H/U FPr, 1997 e TOMAZI, N elson D. "Construções e silêncios sobre a (re)ocupação da região norte do estado do Paraná" In: DIAS, Reginaldo Benedito e GO N ÇALVES, José Henrique Rollo. Maringá e o Norte do Paraná: estudos de história regional. Maringá: EDU EM, 1999.

${ }^{30} \mathrm{D}$ iscussões sobre a construção das memórias constituem alvo de debate e distintas versões. Esse tema é abordado em obras como: FEN ELÓ N , Déa. (org.) Muitas memórias, outras histórias. São Paulo: Editora $O$ lho d'água, 2004; LE GO FF, Jacques. H istória e memória. Campinas: U nicamp, 1996; PO LLACK, Michael. Memória, esquecimento, silêncio. In: Estudos Históricos. Rio de Janeiro, v. 02, n. 03, p. 03-15, 1989; HALBWACHS, Maurice. A memória coletiva. São Paulo: Vértice, 1990; PO LLACK, Michael. Memória e identidade social. In: Estudos Históricos. Rio de Janeiro, v. 05, n. 10, p. 200-212, 1992, entre outras.

${ }^{31} \mathrm{Cf}$. BU RKE, Peter. A alma encantadora das ruas, op. cit., p.3.

${ }^{32}$ Segundo os jornalistas Aristeu Brandespin e A. A. de Assis, esse busto confeccionado em bronze por um artista carioca (desconhecido) encontrava-se numa das estantes de livros da casa de Joubert de C arvalho, em C o pacabana. A o bra foi doada pelo próprio artista para Maringá. Cf. "O s M onumentos de Maringá" In: Tradição. Maringá: Tradição Publicações Ltda., 1987, p. 27.

${ }^{33} \mathrm{~N}$ apo leão Moreira da Silva foi comerciante e vereador - um dos primeiros líderes políticos da cidade.

${ }^{34}$ Esse monumento mantém-se integrado às efemérides celebradas na cidade. Todos os anos (no dia 25 de agosto), cerimônias alusivas ao "Dia do Soldado" são realizadas diante do busto de Caxias. Cf. "O s Monumentos de M aringá" In: Tradição, op. cit., p. 26-27.

${ }^{35}$ Cf. matéria: "O N G pede tombamento da praça", publicada no jornal O D iário do N orte do Paraná, em 09. 11.2005.

${ }^{36}$ Cf. DIAS, op. cit., p. 40-41.

${ }^{37}$ PALLAM IN , op. cit. e SAN TOS, op. cit.

38 "O s Monumentos de Maringá" In: Tradição, op. cit., p. 27.

${ }^{39} \mathrm{~A}$ igreja é decorada com esculturas de Manfred $\mathrm{O}$ sterroht e vitrais de Lorenz $\mathrm{H}$ elmair. U m monumento externo à C atedral, dedicado a N ossa Senhora da Glória, foi inserido mais recentemente de fronte ao pórtico principal. Trata-se da escultura confeccio nada em pedra sabão, por Expedito So breira Ribeiro (oriundo de Porto Firme, Minas gerais). A peça encontra-se num patamar e tem do is metros de altura. Cf. Informações da Secretaria da Prefeitura Municipal de Maringá, disponível em: < http:// www.maringa.pr.gov.br>. Acesso em: dez. 2004.

40 SED U H/PM M. "M emoriais e projetos originais das praças de Maringá 1950-99", op cit.

${ }^{41} 0$ referido engenheiro foi secretário da Coordenadoria de Planejamento e U rbanismo da Prefeitura Municipal de Maringá. Em 1987, ele ocupava o cargo de diretor-presidente da U rbamar - empresa mista constituída para a realização do "Projeto Ágora", responsável pelos planos de reurbanização do centro da cidade. Tal projeto era referido na impressa local como um projeto devotado a "cirurgia plástica" do centro político e administrativo maringaense. Cf. matéria: "A convivência comunitária. Antiga praça se transforma em centro de múltiplas atividades" In: Pois É. M aringá: M RM Ltda., n. 17, p. 21, 1987.

${ }^{42} \mathrm{Cf}$. "Remanejando espaços. Arquitetos transformam duas praças em calçadão e criam um novo ponto de encontro em Maringá" In: Pois É. Maringá: M RM Ltda., ano 2, n. 12, p. 21, 1987.

43 "A convivência comunitária. Antiga praça se transforma em centro de múltiplas atividades" In: Pois É, op. cit, p. 35. 
${ }^{44}$ Segundo o depo imento de moradores mais antigos, o obelisco foi apelidado de "Bicudo" em função de sua forma e pela dificuldade de compreensão do seu significado. Cf. "O s M onumentos de Maringá" In: Tradição, op. cit, p. 27.

${ }^{45} \mathrm{C}$ f. Prédios da cidade na mira do tombamento. O D iário do N orte do Paraná. Maringá, 19.10.2005. ${ }^{46}$ Vasta bibliografia se ocupa do esquadrinhamento do espaço público europeu. Aliás, medidas que também foram adotadas no Brasil, principalmente, nas primeiras décadas do século $X X$. Sobre 0 assunto consultar E.P. Thompson, E. Hobsbawm, M. Foucault, M. Certeau, Margareth Rago, Maria Clementina Pereira C unha, Maria Stella Bresciani, entre outros autores.

${ }^{47} \mathrm{Cf}$. folder do Roteiro Turístico Integrado da Cidade de Maringá, produzido pela Secretaria de Transportes e Turismo do Município, s/d.

${ }^{48} \mathrm{Cf}$. "O s M onumentos de Maringá" In: Tradição, op. cit., p. 27.

49 DE AN GELIS, Bruno Luiz Domingues e DE AN GELIS NETO, Generoso. "Os elementos de desenho das praças de Maringá - Pr" In: Acta Scientiarum, v. 22, n. 5, p. 1445-54, 2000.

50 DIAS, Reginaldo Benedito e GON ÇALVES, José Henrique Rollo. Maringá e o N orte do Paraná: estudos de história regional. Maringá: ED U EM, 1999.

${ }^{51} \mathrm{~N}$ esse perío do foi desenvolvido um projeto de recuperação de foto grafias e objetos relacionados aos primeiros anos de ocupação da cidade.

${ }^{52}$ CALIJU RI, Aninha. "Maringá 57 anos!". Disponível em: http://www.maringa.pr.gov.br. e http:// www.afacci.com.br/novo/a5.htm. Acesso em dez. 2004.

${ }^{53}$ VIO LA, C láudio. Símbolo de Maringá "veste" camisa do time. O D iário do N orte do Paraná, Maringá, 04.11.2005. D ois dias antes, em 02/11/2005, a matéria "Peladão vai receber uniforme do G alo Maringá", redigida por Angelo Rigon, do Maringá N ews, também foi disponibilizada em: http:// www.maringa.newns.com.br. Acesso em nov.2005.

${ }^{54}$ SED U H/PM M. "Memoriais e projetos originais das praças de Maringá 1950-99", op. cit.

55 Id. Ibidem.

${ }^{56} \mathrm{Em}$ áreas de acesso mais restrito, encontramos as pinturas de Luis Bianchini nas paredes do restaurante 0 C asarão (inspiradas em fotografias de antigos moradores) e a coleção particular de aquarelas e óleos so bre tela de Edgar Werner 0 sterroth e de Lilia Lobo. Sob óticas distintas, as narrativas plásticas esbo çam a saga dos primeiros habitantes da região, a força empreendedora do trabalho de pessoas que domesticaram a natureza e trouxeram para a região ares de civilidade. A análise dessas obras esbo çada no capítulo: PELEG RIN I, Sandra C. A. "A paisagem urbana de Maringá expressa em distintas representaçõ es pictóricas da cidade", op. cit., posteriormente foi ampliada na pesquisa "A arqueologia de uma cidade", anteriormente mencionada.

${ }^{57} \mathrm{Cf}$. Depo imentos dos Pioneiros gravados e preservados por meio do "Projeto Memória". Disponível no acervo do Arquivo Municipal de Maringá.

${ }^{58}$ Evidentemente, na maior parte das vezes, observamos que os segmentos de baixa renda tendem a usufruir mais das áreas livres da cidade, visto que estes não dispõem de outros espaços de lazer. 0 s segmentos mais abastados incorporam clubes e shoppings como lugares de sociabilidade argumentando que tais áreas, além de oferecerem diversas atividades lúdicas, ainda garantem maior segurança aos usuários. Esta constatação vem reafirmar que o processo de segregação da sociedade poderia ser minimizado com implantação de novas estruturas capazes de to rnar as praças mais atrativas aos maringaenses. 